\title{
Bronchiolitis obliterans organizing pneumonia associated with chlamydial infection
}

\author{
J-L. Diehl, M. Gisselbrecht, G. Meyer, D. Israel-Biet, H. Sors
}

\begin{abstract}
Bronchiolitis obliterans organizing pneumonia associated with chlamydial infection J-L. Diehl, M. Gisselbrecht, G. Meyer, D. Israel-Biet, H. Sors. (CERS Journals Ltd 1996. ABSTRACT: A 70 year old man presented with symptoms and laboratory findings suggestive of chlamydial pneumonia.

Despite adequate antibiotic therapy, his condition did not improve and transbronchial biopsies disclosed a typical feature of bronchiolitis obliterans organizing pneumonia (BOOP). After initiation of corticosteroid therapy, there were marked clinical and radiographic improvements.

This report demonstrates that chlamydial infection may be associated with BOOP. Eur Respir J., 1996, 9, 1320-1322.
\end{abstract}

Service de Pneumologie et Réanimation, Hôpital Laënnec, Paris, France.

Correspondence: J-L. Diehl, Service de Pneumologie et Réanimation, Hôpital Laënnec, 42 rue de Sèvres, 75007 Paris, France

Keywords: Bronchiolitis obliterans organizing pneumonia, chlamydial infection

Received: July 311995

Accepted after revision January 101996
Bronchiolitis obliterans organizing pneumonia (BOOP) is a clinicopathological entity that occurs in response to a wide variety of pulmonary injuries. It is a nonspecific response, which is histologically characterized by intraluminal fibrosis involving the small conducting airways, alveolar ducts and peribronchial alveolar space [1-3]. Primary disease is either idiopathic or is associated with collagen vascular diseases, drugs and toxins, radiation therapy or infections [4-6]. It has been described in a number of pulmonary bacterial, viral, fungal and protozoal infections. BOOP has been described in association with atypical pneumonia as caused by legionella, Coxiella burnetti and viruses [7-11]. However, little mention can be found in the literature of chlamydiae as an aetiological factor of BOOP. We report a case of BOOP, which appeared to be secondary to a pulmonary chlamydial infection.

\section{Case report}

A 70 year old man was admitted to our institution with a 10 day history of fever, cough, severe sore throat and increasing dyspnoea. A 7 day roxythromycin treatment had been unsuccessful. At the time of admission, his respiratory rate was 36 breaths $\cdot \mathrm{min}^{-1}$ and temperature $38.9^{\circ} \mathrm{C}$. Physical examination revealed sparse crackles over the right lung field. The white blood cell count was 7,800 cells $\cdot \mathrm{mm}^{-3}\left(7.8\right.$ cells $\left.\times 10^{9} \cdot \mathrm{L}^{-1}\right)$, with $71 \%$ neutrophils, $26 \%$ lymphocytes and $3 \%$ monocytes. Chest radiography revealed infiltration of the right lung that was greater in the lower lobe and a right minimal pleural effusion. A pansinusitis was diagnosed on radiographs. Room air arterial blood gas data showed a $\mathrm{pH}$ of 7.45, an arterial oxygen tension $\left(\mathrm{Pa}_{\mathrm{a}} \mathrm{O}_{2}\right)$ of $6.3 \mathrm{kPa}(47 \mathrm{mmHg})$ and an arterial carbon dioxide tension $\left(P \mathrm{a}, \mathrm{CO}_{2}\right)$ of $4.1 \mathrm{kPa}(31$ $\mathrm{mmHg}$ ). Five months before admission, a resection of a prostatic adenoma had been performed and, at that time, the chest radiograph was normal.
The patient underwent a fibreoptic bronchoscopy that revealed a diffuse bronchial inflammation. A protected brush specimen obtained from the right lower lobe remained sterile, as did the pleural fluid. The chlamydia group complement-fixation test was highly positive. The immunofluorescence test was positive for Chlamydia psittaci and Chlamydia trachomatis. The microimmuno-fluorescence test yielded very high titres for Chlamydia pneumoniae (table 1). Serological tests for influenza virus type A, influenza virus type B, parainfluenza virus 1 and 3 , adenoviruses, Legionella and Mycoplasma pneumoniae were negative. Screening serological tests for human immunodeficiency virus 1 and 2 (HIV-1 and HIV-2) were also negative. Antinuclear antibodies were slightly positive (1/50), while anti-deoxyribonucleic acid (DNA) antibodies were negative.

The initial antibiotic therapy consisted in pefloxacin and amoxycillin-clavulanate via intravenous route for 5 days, and was changed to intravenous doxycycline for 21 days when serological results were obtained. Four days later, the patient remained febrile and his clinical condition deteriorated. Erythromycin was added to doxycycline. Continuous positive airway pressure (CPAP) with high inspiratory oxygen fraction $\left(F \mathrm{I}, \mathrm{O}_{2}\right)$ was required.

Table 1. - Serological results for chlamydiae during hospitalization and after recovery (IgG titres)

\begin{tabular}{lcccc}
\hline Time from admission & Day 0 & Day 10 & Day 22 & Day 120 \\
\hline $\begin{array}{l}\text { Chlamydiae complement } \\
\text { fixation test }\end{array}$ & $1 / 160$ & $1 / 160$ & $1 / 160$ & $<1 / 10$ \\
C. psittac (IFT) & $1 / 152$ & $1 / 1024$ & $1 / 512$ & $1 / 64$ \\
C. trachomatis (IFT) & $1 / 512$ & $1 / 1024$ & $1 / 512$ & $1 / 64$ \\
C. pneumoniae (MIFT) & $1 / 2048$ & $1 / 4096$ & $1 / 2048$ & $1 / 28$ \\
\hline
\end{tabular}

IFT: indirect immunoflourescence test; MIF: microimmunoflourescence test; IgG: immunoglobulin G. 


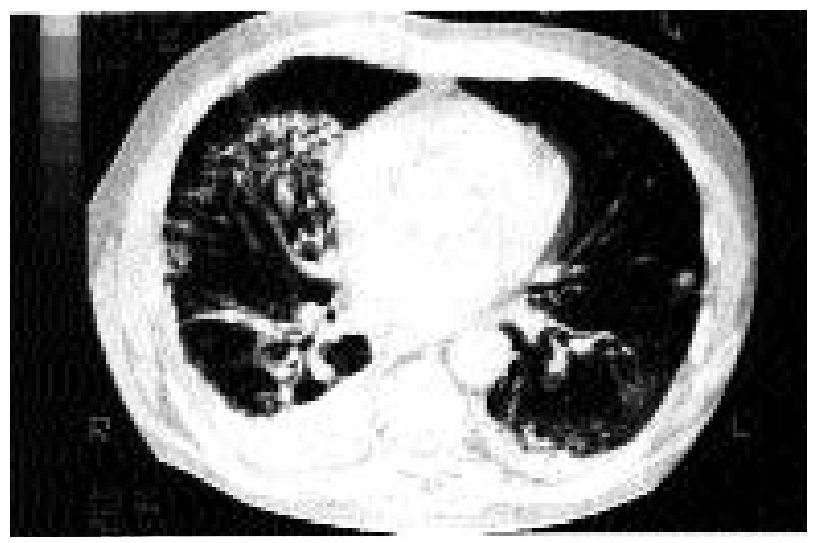

Fig. 1 - Chest computed tomography after the initial course of antibiotic therapy, demonstrating an heterogeneous consolidation, predominantly in the right upper and middle lobes. Areas of subpleural and peribronchovascular consolidations can also be observed. A right pleural effusion is also apparent.

Bronchoalveolar lavage count revealed $313 \times 10^{3}$ cells $\cdot \mathrm{mL}^{-1}$, with $74 \%$ macrophages, $8 \%$ lymphocytes and $18 \%$ neutrophils. No pathogen was identified. Transbronchial lung biopsies revealed inflammatory nonspecific alveolar lesions. Chest computed tomography showed diffuse alveolar infiltrates that were greater in the right upper and middle lobes and a bronchial wall thickening (fig. 1). A trend to honeycomb changes in the right upper lobe was also noted.

During the following 2 weeks, the patient's clinical condition improved slightly, but he remained dyspnoeic and febrile and the chest radiograph was unchanged. Repeated transbronchial lung biopsies revealed a typical feature of BOOP, with intraluminal fibrosis of the distal airspaces (fig. 2). No pathogen was identified on direct examination and cultures. Therapy was completed with prednisone at $1 \mathrm{mg} \cdot \mathrm{kg}^{-1} \cdot \mathrm{day}^{-1}$, leading to a progressive clinical improvement. Ten days after the onset of corticotherapy, arterial blood gas analysis showed a $\mathrm{Pa}, \mathrm{O}_{2}$ of 8.9 $\mathrm{kPa}(67 \mathrm{mmHg}), \mathrm{a} P \mathrm{a}, \mathrm{CO}_{2}$ of $4.9 \mathrm{kPa}(37 \mathrm{mmHg})$, and a $\mathrm{pH}$ of 7.44 with full clinical and chest radiograph recovery. One year after hospital discharge, prednisone had been progressively reduced to $0.15 \mathrm{mg} \cdot \mathrm{kg}^{-1} \cdot \mathrm{day}^{-1}$. No respiratory symptom was observed and the chest radiograph remained normal.

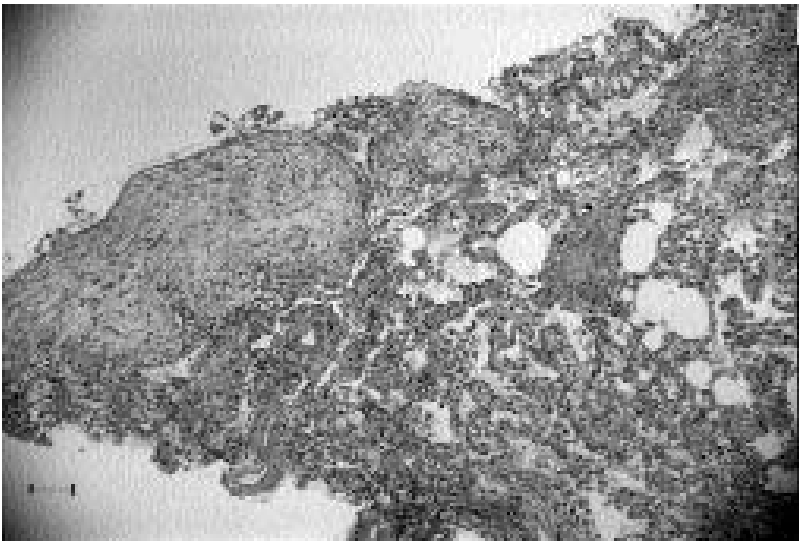

Fig. 2 - Light microscopic section of a repeated transbronchial biopsy, demonstrating patchy large buds of granulation tissue in the distal airspaces. (Haematoxylin and eosin stain; internal scale bar=100 $\mu \mathrm{m}$ ).

\section{Discussion}

We report the findings in a patient with increasing dyspnoea and acute respiratory failure related to chlamydial pneumonitis on serological grounds, with progressive deterioration despite adequate antibiotic therapy. BOOP was documented by transbronchial lung biopsies and the subsequent course was satisfactory under corticotherapy.

BOOP is currently considered as a nonspecific histopathological feature $[1-3,12]$. It is either idiopathic or occurs in association with collagen vascular diseases, hypersensitivity pneumonitis, drugs, toxins, radiation therapy or infections. To our knowledge, there has been a single report of pulmonary chlamydial infection associated with features of BOOP in a patient suffering from Wegener's granulomatosis and with no concurrent pulmonary histological evidence of Wegener's granulomatosis activity [13]. The initial course of our patient was suggestive of atypical pneumonia. The presence of severe sore throat and sinusitis indicated $C$. pneumoniae rather than other chlamydial species, Mycoplasma or Legionella [14]. C. pneumoniae was also very likely to be responsible because of the lack of exposure to birds, the high prevalence of C. pneumoniae and the highest serological titres $[14,15]$. Cross-reactions between species can explain the overall serological results $[15,16]$.

This observation illustrates that bronchiolitis obliterans organizing pneumonia should be considered in cases of unusual radiographic aspect or of chronic evolution of chlamydial pneumonitis and, conversely, that appropriate serological tests should be part of the aetiological search in cases of bronchiolitis obliterans organizing pneumonia of unknown origin.

\section{References}

1. Epler GR, Colby TV, McLoud TC, Carrington CB, Gaensler EA. Bronchiolitis obliterans organizing pneumonia. N Engl J Med 1985; 312: 152-158.

2. Guerry-Force ML, Müller NL, Wright JL, et al. A comparison of bronchiolitis obliterans with organizing pneumonia, usual interstitial pneumonia and small airways disease. Am Rev Respir Dis 1987; 135: 705-712.

3. Cordier JF, Loire R, Brune J. Idiopathic bronchiolitis obliterans organizing pneumonia. Chest 1989; 96: 999-1004.

4. Crestani B, Kambouchner M, Soler P, et al. Migratory bronchiolitis obliterans organizing pneumonia after unilateral radiation therapy for breast carcinoma. Eur Respir $J$ 1995; 8: 318-321.

5. Bayle JY, Nesme P, Bejui-Thivolet F, Loire R, Guerin JC, Cordier JF. Migratory organizing pneumonitis primed by radiation therapy. Eur Respir J 1995; 8: 322-326.

6. Valle JM, Alvarez D, Autuney J. BOOP secondary to amiodarone. Eur Respir J 1995; 8: 470-471.

7. Nikki P, Meretoza O, Valtonen V, et al. Severe bronchiolitis probably caused by varicella zoster virus. Crit Care Med 1982; 10: 344-346.

8. Jannigan DT, Marrie TJ. An inflammatory pseudotumor of the lung in Q fever pneumonia. N Engl J Med 1983; 308: 86-88.

9. Sato P, Madtes DK, Thorning D, Albert RK. Bronchiolitis obliterans caused by Legionella pneumophila. Chest 1985; 87: 840-842. 
10. Laraya-Cuasay LR, De Forest A, Huff D, Lischner H, Huang NH. Chronic pulmonary complications of early influenza virus infection in children. Am Rev Respir Dis 1977; 116: 617-625.

11. Chastre J, Raghu G, Soler P, Brun P, Basset F, Gibert C. Pulmonary fibrosis following pneumonia due to acute Legionnaires' disease: clinical, ultrastructural and immunofluorescent study. Chest 1987; 91: 57-62.

12. Basset F, Ferrans VJ, Soler P, Takemura T, Eukuda Y, Crystal RG. Intraluminal fibrosis in interstitial lung disorders. Am J Pathol 1986; 122: 443-461.
13. Case record of the Massachusetts general hospital. N Engl J Med 1990; 323: 1546-1555.

14. Grayston JT, Kuo C, Wang S, Altman J. A new Chlamydia psittaci strain, TWAR, isolated in acute respiratory tract infections. N Engl J Med 1986; 315: 161-168.

15. Cook PJ, Honeybourne D. Chlamydia pneumoniae: a review. J Antimicrob Chemother 1994; 34: 859-873.

16. Kern DG, Neill MA, Schachter J. A seroepidemiologic study of Chlamydia pneumoniae in Rhode Island: evidence of serologic cross-reactivity. Chest 1993; 104 : 208-213. 